\title{
Lead-Catalyzed Synthesis of Azo Compounds by Ammonium Acetate Reduction of Aromatic Nitro Compounds
}

\author{
G. R. Srinivasa , K. Abiraj \& D. Channe Gowda
}

To cite this article: G. R. Srinivasa , K. Abiraj \& D. Channe Gowda (2003) Lead-Catalyzed Synthesis of Azo Compounds by Ammonium Acetate Reduction of Aromatic Nitro Compounds, Synthetic Communications, 33:24, 4221-4227, DOI: 10.1081/SCC-120026850

To link to this article: https://doi.org/10.1081/SCC-120026850

曲 Published online: 21 Aug 2006.

Submit your article to this journal ๘

Џ Article views: 297

Q View related articles $\longleftarrow$

Citing articles: 17 View citing articles $\sqsubset$ 
()2003 Marcel Dekker, Inc. All rights reserved. This material may not be used or reproduced in any form without the express written permission of Marcel Dekker, Inc.

SYNTHETIC COMMUNICATIONS ${ }^{\circledR}$

Vol. 33, No. 24, pp. 4221-4227, 2003

\title{
Lead-Catalyzed Synthesis of Azo Compounds by Ammonium Acetate Reduction of Aromatic Nitro Compounds
}

\author{
G. R. Srinivasa, K. Abiraj, and D. Channe Gowda* \\ Department of Studies in Chemistry, University of \\ Mysore, Manasagangotri, Mysore, Karnataka, India
}

\begin{abstract}
Lead/ammonium acetate is a convenient reagent for the reduction of aromatic nitro compounds to the corresponding symmetrically substituted azo compounds. Various azo compounds containing additional reducible substituents such as halogen, nitrile, acid, phenol, ester, methoxy, etc., functions have been synthesized in a single step by the use of this reagent. The conversion is reasonably fast, clean, high yielding and occurs at room temperature in methanol.

Key Words: Catalytic transfer hydrogenation; Nitro compounds; Azo compounds; Lead; Ammonium acetate.
\end{abstract}

*Correspondence: D. Channe Gowda, Department of Studies in Chemistry, University of Mysore, Manasagangotri, Mysore, Karnataka, India-570 006; Fax: 091-0821-2421263/2518835; E-mail: dcgowda@yahoo.com.

\section{1}

DOI: $10.1081 / \mathrm{SCC}-120026850$

Copyright ( 2003 by Marcel Dekker, Inc.
0039-7911 (Print); 1532-2432 (Online) www.dekker.com 
Azo compounds have been widely utilized as dyes and analytical reagents. They can also be used as indicators in chemical laboratories and as stains in biological field. There are many methods available for the synthesis of azo compounds. ${ }^{[1-5]}$ Most of the methods documented in the literature are associated with cyclization, rearrangement, and isomerization in strong acid and alkaline medium.

Although there are a good number of methods available for the reduction of organic compounds, ${ }^{[6]}$ there still remain the important problems of reaction, i.e., many of them need drastic conditions and/or costly reagents. Catalytic hydrogenation is also commonly used, ${ }^{[7]}$ although the success of reaction is sensitive towards catalyst, solvent, and substrate. Further, catalytic hydrogenation employs highly diffusible, low molecular weight, flammable hydrogen gas, and requires pressure equipment. Nowadays, heterogeneous catalytic transfer hydrogenation method has proved to be a potent choice for reduction of organic compounds. ${ }^{[8-13]}$ In comparison with catalytic hydrogenation or with other methods of reduction, catalytic transfer hydrogenation has many real and potential advantages such as: (i) low cost, (ii) rapidity, (iii) mild conditions, usually avoiding strong acid or base, (iv) selectivity, (v) simple operation and work up, and (vi) broad applicability.

The earlier works showed that ammonium acetate was useful reagent in the synthesis of many organic compound ${ }^{[14,15]}$ including $\beta$-amino acids. ${ }^{[16]}$ Lead and its compounds ${ }^{[17-20]}$ are widely used in organic synthesis. Lead powder is used to deactivate the catalytic activity of palladium. These modified palladium catalysts are used to reduce alkynes to alkenes. ${ }^{[9]}$ Here we wish to report the synthesis of azo compounds by catalytic transfer hydrogenation of nitro arenes by using lead powder with ammonium acetate in methanol at room temperature (Sch. 1). Various azo compounds containing additional reducible substituents such as halogen, nitrile, acid, phenol, ester, methoxy, etc., functions have been synthesized in a single step.

Inspection of the data in Table 1 clearly shows that the method can be conveniently applied for the synthesis of several structurally different symmetrically substituted azo compounds. Synthesis of unsymmetrically

\author{
$2 \mathrm{X}-\mathrm{Ar}_{-} \mathrm{NO}_{2} \underset{\mathrm{MeOH} \text {, r. t. }}{\stackrel{\mathrm{CH}_{3} \mathrm{CO}_{2} \mathrm{NH}_{4} / \mathrm{Pb}}{\longrightarrow}} \mathrm{X}-\mathrm{Ar}-\mathrm{N}=\mathrm{N}-\mathrm{Ar}-\mathrm{X}$ \\ $\mathrm{X}=-\mathrm{Cl},-\mathrm{Br},-\mathrm{CN},-\mathrm{CH}_{3},-\mathrm{OCH}_{3},-\mathrm{CO}_{2} \mathrm{H},-\mathrm{COCH}_{3},-\mathrm{OH}$ etc.
}

Scheme 1. 
Table 1. Reduction of nitro compounds to azo compounds using $\mathrm{CH}_{3} \mathrm{CO}_{2} \mathrm{NH}_{4} / \mathrm{Pb}$.

\begin{tabular}{|c|c|c|c|c|c|}
\hline \multirow[b]{2}{*}{ Nitro compound } & \multirow{2}{*}{$\begin{array}{l}\text { Time } \\
\text { (in h) }\end{array}$} & \multirow[b]{2}{*}{ Product } & \multirow{2}{*}{$\begin{array}{l}\text { Yield } \\
(\%)^{\mathrm{a}}\end{array}$} & \multicolumn{2}{|c|}{ Melting point $\left({ }^{\circ} \mathrm{C}\right)$} \\
\hline & & & & Found & Lit. $^{[21]}$ \\
\hline Nitrobenzene & 2.0 & Azobenzene & 91 & $66-67$ & 68 \\
\hline$p$-Nitrobiphenyl & 2.4 & Azobiphenyl & 87 & $248-250$ & 250 \\
\hline$p$-Nitrophenol & 2.5 & $2,2^{\prime}$-Dihydroxyazobenzene & 90 & $174-175$ & $173-175$ \\
\hline$o$-Nitrotoluene & 2.8 & 2,2'-Dimethylazobenzene & 91 & $54-55$ & 55 \\
\hline$m$-Nitrotoluene & 2.4 & 3,3'-Dimethylazobenzene & 93 & $55-56$ & 55 \\
\hline$m$-Nitroanisole & 2.0 & $3,3^{\prime}$-Diethoxyazobenzene & 89 & $90-92$ & 91 \\
\hline$m$-Chloronitrobenzene & 2.0 & 3,3'-Dichloroazobenzene & 87 & $101-102$ & 101 \\
\hline$o$-Nitroanisole & 2.2 & $2,2^{\prime}$-Diethoxyazobenzene & 80 & $130-132$ & 131 \\
\hline$o$-Chloronitrobenzene & 3.0 & $2,2^{\prime}$-Dichloroazobenzene & 90 & $135-138$ & 137 \\
\hline$p$-Nitrotoluene & 2.6 & 4,4'-Dimethylazobenzene & 89 & $144-146$ & 144 \\
\hline$p$-Ethoxynitrobenzene & 3.0 & $4,4^{\prime}$-Diethoxyazobenzene & 82 & $159-162$ & 160 \\
\hline$p$-Chloronitrobenzene & 2.0 & 4,4'-Dichloroazobenzene & 82 & $185-187$ & 188 \\
\hline 1-Nitronaphthalene & 3.0 & $1,1^{\prime}$-Azonaphthalene & 90 & $188-191$ & 190 \\
\hline 2-Nitronaphthalene & 2.8 & $2,2^{\prime}$-Azonaphthalene & 91 & $207-209$ & 208 \\
\hline
\end{tabular}

${ }^{\mathrm{a}}$ Yields of isolated pure products.

${ }^{1} \mathrm{H}$ NMR spectra were obtained on an $\mathrm{AMX}-400 \mathrm{MHz}$ spectrometer in $\mathrm{CDCl}_{3}$ as the solvent and TMS as internal standard. All of the products are known and the isolated products gave IR spectra in agreement with their structures.

substituted azo compounds leads to the formation of a mixture, which needs extensive purification and yields are low (less than 30\%). This new system reduced with ease a wide variety of nitro compounds to the corresponding azo compounds and many other reducible functional groups being tolerated. The reduction of nitro compounds to azo compounds was completed within $2-3 \mathrm{~h}$. The course of reaction was monitored by TLC and IR spectra. The disappearance of asymmetric and symmetric stretching bands near 1520 and $1345 \mathrm{~cm}^{-1}$ due to $\mathrm{N} \ldots \ldots . \mathrm{O}$ of $\mathrm{NO}_{2}$ and appearance of a strong band between 1630 and $1575 \mathrm{~cm}^{-1}$ due to $\mathrm{N}=\mathrm{N}$ stretching in IR spectra clearly indicates the conversion. The work-up and isolation of the products were easy. Thus all the compounds reduced to azo compounds were characterized by comparison of their TLC, IR spectra, ${ }^{1} \mathrm{H}$ NMR spectra, and melting points with authentic samples. A control experiment was carried out using nitro compounds with ammonium acetate but without lead powder, did not yield the desired product. Further, another control experiment was also carried out using nitro compound with lead powder in the absence of ammonium acetate was also not yielded the desired product. 
The mechanism for the formation of azo compound probably involves initial reduction of nitro compound to nitroso and hydroxylamine products, which then condense to form azo compounds. This is evidenced by the isolation and characterization of the intermediate hydroxylamine compounds. Ammonium acetate in the presence of palladium on carbon or zinc directly converts nitro compounds into amines (Gowda et al., personal communication). However, lead being a weak catalyst cannot efficiently reduce the intermediate azo compounds to amines. However, $4-6 \%$ of amino product was obtained along with major azo product. The percentage of amino compounds increased up to $20 \%$ if the reaction mixture was stirred for very long time.

The scope of this new general procedure is shown in Table 1. In most cases the reactions were completed within $2-3 \mathrm{~h}$. The lead powder can be reused after thorough washing. These results demonstrate a rapid versatile and selective reducing system for wide variety of nitro compounds in the presence of other functional groups for e.g., halogens, $-\mathrm{CN},-\mathrm{CH}_{3}$, $-\mathrm{OCH}_{3},-\mathrm{CO}_{2} \mathrm{H},-\mathrm{COCH}_{3},-\mathrm{OH}$ etc. The reduction was also carried out with the nitro compounds bearing bromomethyl sulphonic acid, oximino, amino, and dialkyl amino groups. In these cases, the bromo methyl, dialkyl amino, and oximino groups are compatible under the experimental conditions. But, in the case of amino substituted nitro compounds, mixtures of products are yielded, probably due to the coupling of reduction intermediates with the free amino group. Nitro sulphonic acids gave precipitate, which are insoluble in the solvents employed and thus, this procedure is not helpful to such type of compounds for obtaining azo compounds. This procedure will therefore be of general use for the preparation of azo compounds, specifically in cases where mild reaction condition is required and it is less expensive compared to existing methods.

\section{EXPERIMENTAL}

\section{Materials}

All the nitro compounds and ammonium acetate were purchased from Aldrich Chemical Company (USA). Lead powder (325 mesh size, 99.5\% pure, packed under argon) was purchased from SISCO Research Laboratories Pvt. Ltd., Bombay (India). All the solvents used were of analytical grade or were purified according to standard procedures. TLC was carried out on silica gel plates obtained from Whatman Inc. The 
melting points were determined by using Thomas-Hoover melting point apparatus and are uncorrected. IR spectra were recorded on SHIMADZU FTIR-8300 spectrometer. For preparative TLC, the plates were prepared from Kieselgel $60 \mathrm{GF}_{254}$, Merck, Darmstadt and for column chromatography 60-120 mesh silica gel was used obtained from SISCO Research Laboratories.

\section{Typical Procedure}

A suspension of an appropriate nitro compound $(10 \mathrm{mmol})$ and lead powder $(30 \mathrm{mmol})$ in methanol $(15 \mathrm{~mL})$ was stirred with ammonium acetate $(20 \mathrm{mmol})$ under nitrogen atmosphere at room temperature. After the completion of the reaction (monitored by TLC), the reaction mixture was filtered through celite pad, washed with solvent. The combined filtrate and washings are evaporated under vacuum. The residue was taken in to $30 \mathrm{~mL}$ chloroform or ether, washed twice with $30 \mathrm{~mL}$ saturated brine solution and finally with water. The organic layer was dried over anhydrous magnesium sulphate and evaporation of the organic layer followed by purification either by preparative TLC or by column chromatography to yield the desired product.

\section{ACKNOWLEDGMENT}

The authors wish to thank University Grants Commission, New Delhi, India for providing financial assistance.

\section{REFERENCES}

1. Vogel, A.I.; Wating, A.; Wating, J. The small-scale preparation of azobenzene and of hydrazobenzene. J. Chem. Edu. 1958, 35, 40-41.

2. Moore, R.E.; Furst, A. Reductions with hydrazine hydrate catalyzed by Raney nickel. III. Effect of the catalyst on the reduction of 2,2'dinitrobiphenyl. J. Org. Chem. 1958, 23, 1504-1506.

3. Hutchins, R.O.; Lamson, D.W.; Rua, L.; Cynthia, M.; Bruce, M. Reduction of aromatic nitro compounds with sodium borohydride in dimethyl sulphoxide or sulpholane. Synthesis of azo or azoxy derivatives. J. Org. Chem. 1971, 36, 803-806. 
4. Kabalka, G.W.; Varma, R.S. Reduction of nitro and nitroso compounds. In Comprehensive Organic Synthesis; Fleming, I., Ed.; Pergamon Press: Oxford, UK, 1991; Vol. 8, Ch. 2.2, 363-380.

5. Kirk-Othmer's Encyclopedia of Chemical Technology, 4th Ed.; Grant, M.H., Ed.; John Wiley \& Sons: New York, 1992; Vol. 3, 821-875.

6. Comprehensive Organic Synthesis; Fleming, I., Ed.; Pergamon Press: Oxford, UK, 1991; Vol. 8, (Reduction).

7. Rylander, P.N. In Hydrogenation Methods; Academic Press: New York, 1985; 365 pp.

8. Brieger, G.; Nestrick, T.J. Catalytic transfer hydrogenation. Chem. Rev. 1974, 74, 567-580.

9. Johnstone, R.A.W.; Wilby, A.H.; Entwistle, I.D. Heterogeneous catalytic transfer hydrogenation and its relation to other methods for reduction of organic compounds. Chem. Rev. 1985, 85, 129-170.

10. Ram, S.; Ehrenkaufer, R.E. Ammonium formate in organic synthesis: a versatile agent in catalytic transfer hydrogenation. Synthesis 1988, 91-95.

11. Jnaneshwara, G.K.; Sudalai, A.; Deshpande, V.H. Palladium catalyzed transfer hydrogenation of azo compounds and oximes using ammonium formate. J. Chem. Res. (S) 1998, (3), 160-161.

12. Gowda, S.; Abiraj, K.; Gowda, D.C. Reductive cleavage of azo compounds catalyzed by commercial zinc dust, using ammonium formate or formic acid. Tetrahedron Lett. 2002, 43, 1329-1331.

13. Gowda, S.; Gowda, D.C. Application of hydrazinium monoformate as new hydrogen donor with Raney nickel; a facile reduction of nitro and nitrile moieties. Tetrahedron 2002, 58 (11), 2211-2213.

14. Ringold, H.J.; Loken, B.; Rosenkranz, G.; Sondheimer, F. The direct oppenauer oxidation of steroidal formate esters. A new synthesis of $17 \alpha$-hydroxyprogesterone. J. Am. Chem. Soc. 1956, 78, 816-819.

15. Finan, P.A.; Fothergill, G.A. The preparation of acid amides from acid chlorides. J. Chem. Soc. 1962, 2824-2825.

16. Lazar, L.; Martinek, T.; Bernath, G.; Fulop, F. A simple synthesis of $\beta$-alkyl-substituted $\beta$-amino acids. Synth. Commun. 1998, 28, 219-224.

17. March, J. In Advanced Organic Chemistry; Wiley Eastern Ltd.: New Delhi, 1986; 1223, 1172 pp.

18. Leonard, N.J.; Swann, S., Jr.; Fuller, G. The electrolytic reduction of tricyclic $\alpha$-amino ketones. Synthesis of medium rings containing nitrogen. J. Am. Chem. Soc. 1954, 76, 3193-3197.

19. Gakenheimer, W.C.; Hartung, W.H. The synthesis of aliphatic amino alcohols of pharmacological interest. J. Org. Chem. 1944, 9, 85-88. 
()2003 Marcel Dekker, Inc. All rights reserved. This material may not be used or reproduced in any form without the express written permission of Marcel Dekker, Inc.

20. Azoo, J.A.; Grimshaw, J. Lead as a reducing agent in the preparation of bibenzyls and aromatic azoxy compounds. J. Chem. Soc. (C) 1968, 2403-2405.

21. Vogel, A.I. In Text Book of Practical Organic Chemistry; Addison Wesley Longman Limited: UK, 1997; 1298 pp.

Received in the UK July 4, 2003 


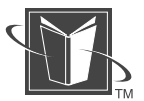

Marcel DekKer, Inc. • 270 Madison AVEnUe • NeW York, NY 10016

C2003 Marcel Dekker, Inc. All rights reserved. This material may not be used or reproduced in any form without the express written permission of Marcel Dekker, Inc. 